\title{
Airborne RF Measurement System and Analysis of Representative Flight RF Environment
}

\author{
Sandra V. Koppen, Jay J. Ely, Laura J. Smith, \\ Richard A. Jones, Vincent J. Fleck \\ NASA Langley Research Center, Hampton, Virginia
}

\author{
Maria Theresa Salud, John Mielnik \\ Lockheed Martin Corporation, Hampton, Virginia
}

\begin{abstract}
Environmental radio frequency (RF) data over a broad band of frequencies were needed to evaluate the airspace around several airports. An RF signal measurement system was designed using a spectrum analyzer connected to an aircraft VHF/UHF navigation antenna installed on a small aircraft. This paper presents an overview of the RF measurement system and provides analysis of a sample of RF signal measurement data over a frequency range of $30 \mathrm{MHz}$ to $1000 \mathrm{MHz}$.
\end{abstract} ILS

Keywords- aircraft, EMC, EMI, CNS, RF, radio, measurement,

\section{INTRODUCTION}

The National Airspace System (NAS) is becoming increasingly dependent upon radio-based communication, navigation and surveillance (CNS) services between aircraft, ground and satellite infrastructure. Radio frequency (RF) electromagnetic compatibility (EMC) between radio-based CNS services and the electromagnetic environment is important for management of the current and future RF environment for aeronautics and space.

As part of NASA's mission to develop technologies for safer aircraft, the agency is conducting research in electromagnetic threats and hazards to safe flight. Development of the Airborne RF Measurement System (ARMS) is part of this effort. The purpose of the ARMS is to provide a resource for environmental electromagnetic measurements. It can be used to investigate high-intensity radiated fields (HIRF) and RF spectrum encroachments. Recently, the ARMS was used during a flight RF measurement survey to evaluate the electromagnetic environment in the airspace during approaches to a local airfield.

An overview of the ARMS and its installation on NASA Langley Research Center's Lancair Columbia 300 aircraft is presented. Sample data acquired during the flight experiment is analyzed and presented. The application of calibrations for the flight experiment is also discussed. Details of the ARMS installation package, data analysis, and the application of data calibrations are presented in [1].

\section{SYSTEM DESCRIPTION}

\section{A. Overview}

The Lancair Columbia 300 aircraft was selected as the research aircraft to host the ARMS because of its operational capabilities, low fuel consumption, availability, and acceptable cargo capacity. Operationally, the Lancair aircraft provided instrumentation for acquiring Global Positioning System (GPS) data and performing precision approaches and landings. Other operational advantages included two identical navigation (NAV) and communication (COM) radio units, easily accessible avionics equipment, and speed and altitude performance suitable for experiment measurements.

Fig. 1 is a block diagram illustrating the ARMS installation package for the Lancair aircraft and the aircraft equipment used. The ARMS installation package is comprised of four elements: research electrical power and data communication interfaces, mechanical system, instrumentation, and software. The ARMS utilizes aircraft equipment resources to provide electrical power and data communication interfaces. It also uses aircraft antennas and receivers for acquiring RF signals, GPS data, and for performing precision approaches and landings. The ARMS installation package provided the ability to monitor, collect, and record RF signal measurements and GPS data.

\section{B. Electrical System}

The Lancair aircraft's baseline research electrical system was modified to accommodate the ARMS' requirements. The research electrical system, based on the General Aviation Baseline Research System (GABRS) [2], provides an independent source of electrical power for the research system while maintaining isolation from the basic aircraft's electrical system. The research power system provides $50 \mathrm{~A}$ at $28 \mathrm{VDC}$. A converter was added to supply 12 and 14 VDC to the ARMS research equipment.

Fig. 2 illustrates the ARMS measurement instrumentation, data interfaces (dashed), and the aircraft's GPS and NAV systems. The laptop computer communicates with the spectrum analyzer via an IEEE General Purpose Interface Bus (GPIB) to collect RF measurement data and to control the spectrum analyzer (SA) parameters. GPS data is collected by the laptop computer using an IEEE RS-232 interface connected to the aircraft's GPS system via a research pallet. RF signals are received using the aircraft's NAV antenna, a Comant CI 159C dual-band V-Dipole, for Very High Frequency OmniRange (VOR), Localizer (LOC), and Glideslope (GS) bands. The RF signal was obtained by using the secondary output of the NAV antenna splitter and connecting to the RF input of the spectrum analyzer. The NAV antenna is located on the

Identify applicable sponsor/s here. (sponsors) 


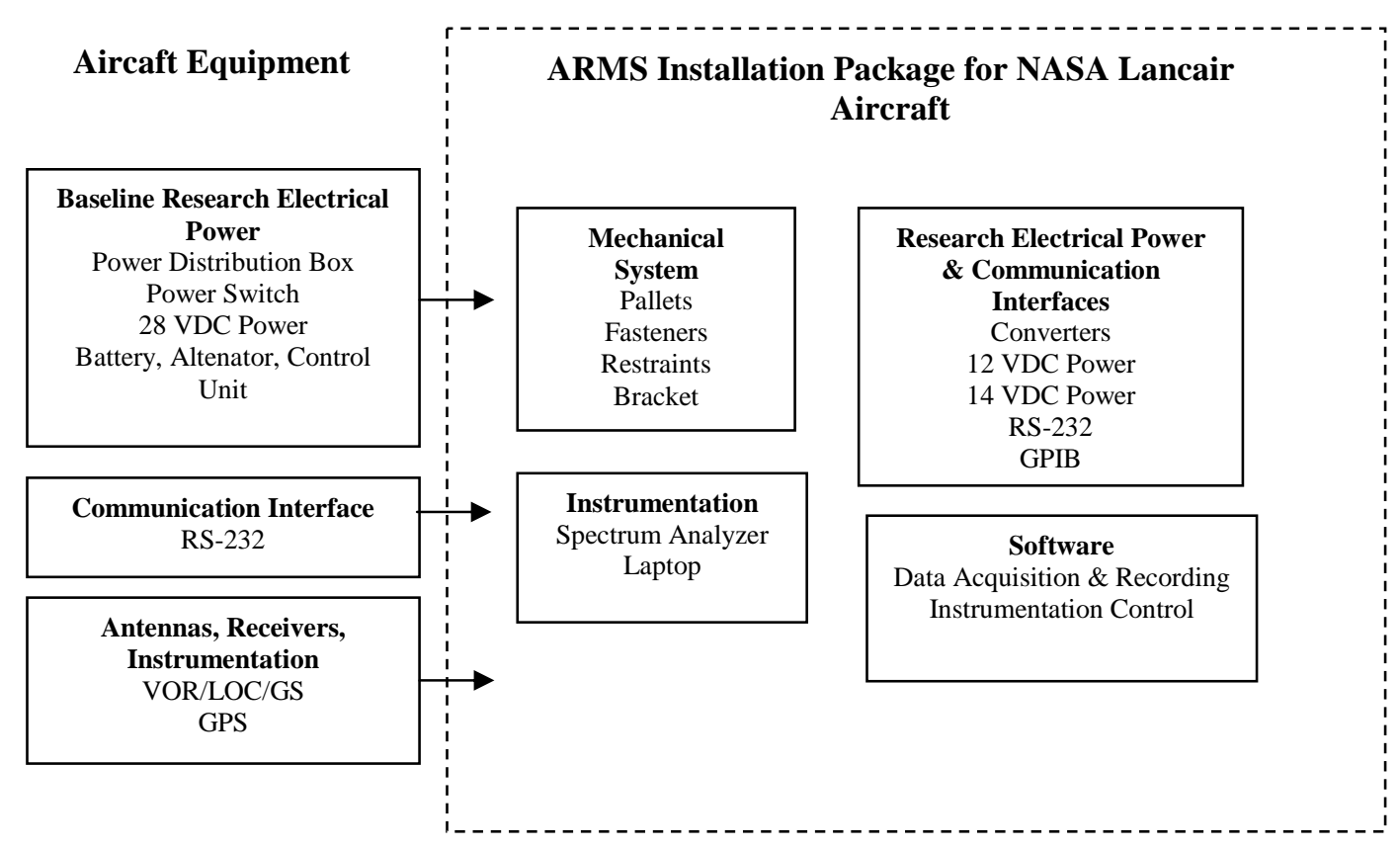

Figure 1: ARMS installation package on NASA Lancair aircraft.

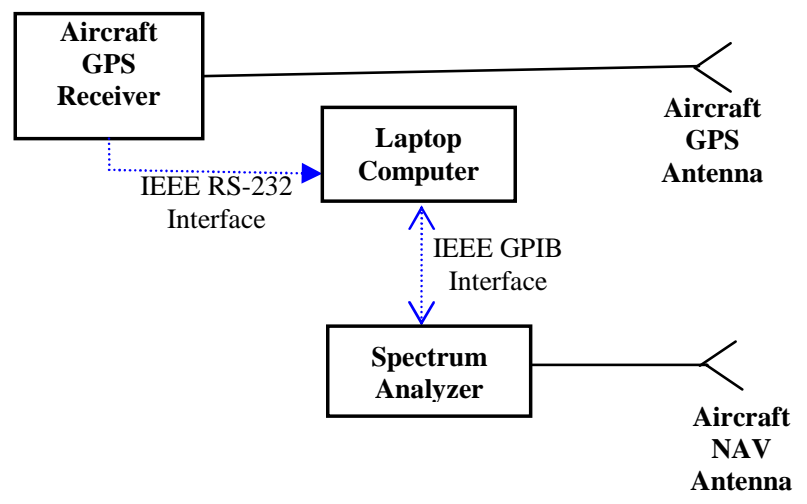

directly behind the pilot's seat. Existing seat belt hard points and other mounting points were utilized for installation purposes. A side pallet was designed and installed for mounting the laptop computer. It utilized existing rear seat belt brackets and required the removal of the left passenger seat.

Figure 2: ARMS measurement instrumentation and communication interfaces.

aircraft's tail in a horizontal position (Fig. 3). The GPS antenna is located inside the aft fuselage which is of composite construction. The installed ARMS instrumentation is shown in Fig. 4, including the SA, laptop computer, and a central research power control panel located on the middle console that was used to switch on power for equipment and also served as an emergency cutoff switch.

\section{Mechanical System}

The ARMS mechanical system accommodated the installation of research equipment and applied safety requirements based on FAA regulations [3][4][5] to the new aircraft configuration. Equipment pallets and restraints were designed and incorporated into the aircraft to accommodate research equipment. Analyses were performed to determine load conditions based on the addition of brackets, pallets, and equipment. The spectrum analyzer was mounted on the floor

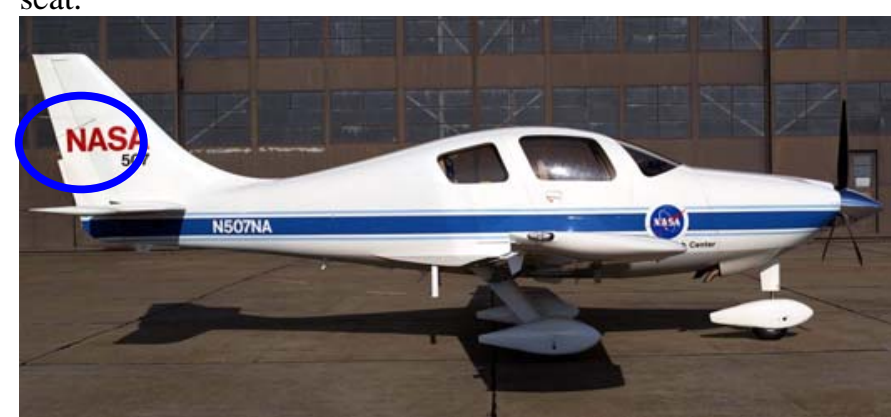

Figure 3: Lancair Columbia 300 aircraft and NAV antenna located on tail (blue ellipse).

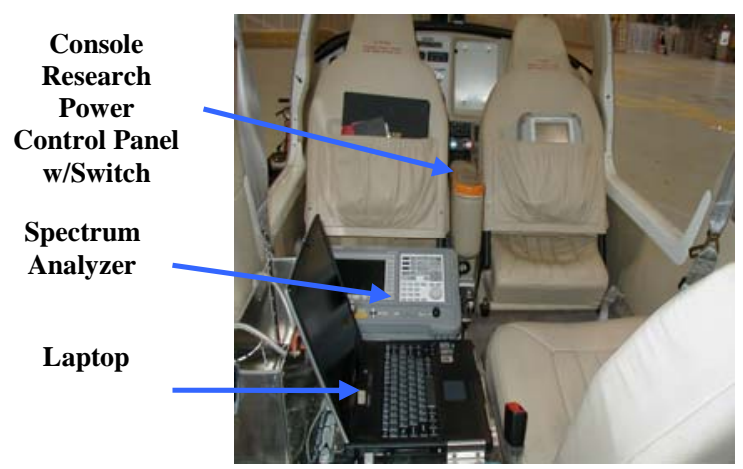

Figure 4: Installation of ARMS test equipment on the Lancair Columbia 300 aircraft. 


\section{Software}

The "Aircraft Spectrum Monitor" software module provided automated instrument control, data acquisition, and recording. The software module continuously acquired and displayed SA, test, and GPS data and recorded and saved data on the laptop computer in Microsoft Excel ${ }^{\mathrm{TM}}$ format for later analysis. In addition, a list of selectable geographic end points defined by latitude and longitude coordinates, position, and distance to end point (runway reference coordinates) were provided. Altitude is computed during data post processing using approach and distance information recorded in the data files. The software applies frequencies and power losses/gains to measured data to correct for receive path loss and antenna gain.

\section{ELECTROMAGNETIC INTERFERENCE (EMI) TEST}

An aircraft-level electromagnetic interference (EMI) test was performed with the ARMS measurement test instrumentation installed. The purpose of the test was to assess the EMI impact of the flight research system on the aircraft's communication and navigation systems. Results of the COM/NAV receiver EMI tests indicated that the ARMS did not produce any emissions that exceeded the appropriate receiver's noise measurement threshold, therefore no ground or flight radio checks were required.

\section{Flight RF SuRVEY: MEASUREMENT Method}

Measurements were made from the Lancair aircraft on approach to an airport runway. Federal Aviation Administration (FAA) Instrument Approach Procedures (IAP's) were used for each airport included in the aerial RF measurement survey. The following types of IAP's were used for approaches and landings: VOR, GPS, and instrument landing system (ILS) using GS and LOC. The primary focus of the survey was the accurate measurement of LOC and GS signal levels using the ILS IAP's. GPS approaches were flown to provide an alternative aircraft glidepath for data comparison to ILS IAP's. VOR approaches were also flown at airports where it was available. Data were collected during either "long range" (25 miles) or "normal" (3 miles) approaches to designated airports.

During selected ILS, GPS, and VOR IAP's, RF site survey data were measured using the aircraft's NAV antenna over a broad band of frequencies (30 MHz to $1000 \mathrm{MHz}$ ). Additionally, GS and LOC RF signal measurements were made during ILS approaches using narrower frequency ranges. The narrow band measurements were used to validate the broad band data. The narrower frequency ranges selected were dependent on the airport's LOC or GS channels. These frequency ranges were created by applying 2 $\mathrm{kHz}$ to either side of the tunable LOC and GS channels. No VOR narrow band data was collected. In addition to Excel files, data was recorded in a test log book that included time, altitude, airspeed, and distance-to-runway.

\section{FLIGHT RF SURVEY: FULL SPECTRUM DATA AND ANALYSIS FOR TYPICAL APPROACH}

Flight RF measurement data was collected using the ARMS during 43 landing approaches at four different airfields. Representative data from a single ILS landing approach at one airport is presented.

The ILS approach and landing captured thirteen minutes of measurement data including a 250 second taxi from runway to a hangar. The measurements are subject to the directivity and efficiency characteristics of the aircraft's navigation antenna. The application of antenna calibrations is needed in order to utilize data for any purpose other than to determine the presence or absence of signals. The data presented in Figs. 5, 6, and 7 do not have antenna calibrations applied, as the purpose of the flight survey was to observe signals and their relative levels.

Fig. 5 illustrates data collected over the entire frequency range observed (30 $\mathrm{MHz}$ to $1000 \mathrm{MHz}$ ) during an approach \& landing. The data images presented show signal amplitude versus frequency and time. The color-bar to the right of the plot represents the amplitude of the signal received. The low-end (dark blue) of the measured spectrum represents the noise floor. Below each data image, there is an altitude plot with the same time-scale.

Fig. 5 and Table 1 reveal significant information about the RF spectrum in a typical suburban environment. Table 1 groups the RF spectrum from $30 \mathrm{MHz}$ to $1000 \mathrm{MHz}$ into 10 allocation bands and summarizes the various applications within each band. [6] was used to obtain RF band summary information used in Table 1. It is evident that the FM Broadcast Radio band and the Television bands are "always on", whereas most other RF bands are less frequently used. Note how most signal levels decline significantly upon landing (about 500 seconds into the data). The higher signal levels before landing shows that virtually all signals can be detected more easily when the receive antenna is at higher altitude.

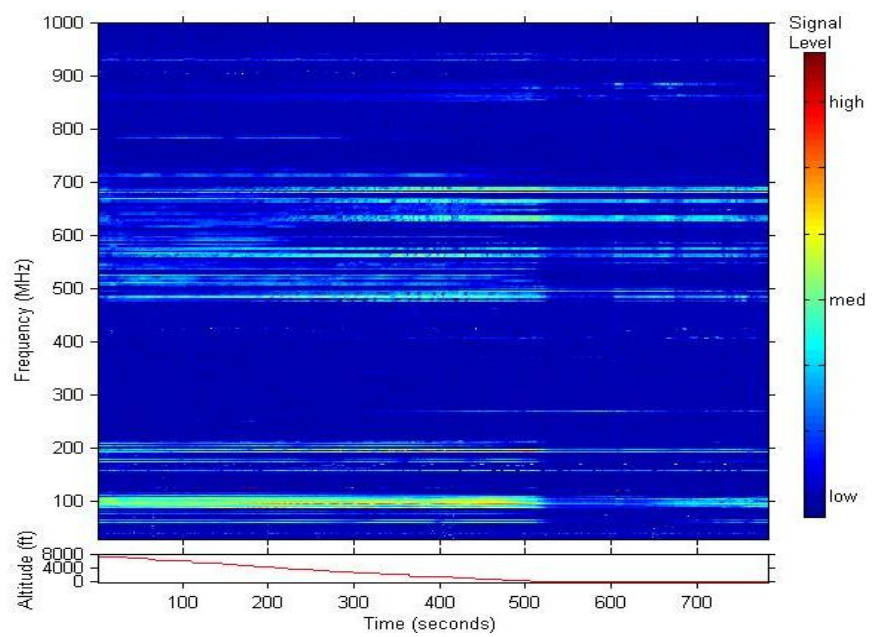

Figure 5: In-Flight Spectrum Environment for 30 to 1000 $\mathrm{MHz}$. 
Table 1: Frequency Allocation Summary for $30-1000$

$\mathrm{MHz}$

\begin{tabular}{|c|c|}
\hline $\begin{array}{c}\text { Frequency } \\
\text { Band (MHz) }\end{array}$ & Use Summary \\
\hline $30-88$ & $\begin{array}{c}\text { Cordless Phones, Baby Monitors, } \\
\text { Amateur radio, TV Channels 2 to 6 }\end{array}$ \\
\hline $88-108$ & FM Broadcast Radio \\
\hline $108-138$ & $\begin{array}{c}\text { Aeronautical Navigation and } \\
\text { Communication }\end{array}$ \\
\hline $138-174$ & $\begin{array}{c}\text { Civil Air Patrol, U. S. Coast } \\
\text { Guard, ATC, Navy, Local } \\
\text { Government., LoJack, Weather } \\
\text { Radio, Emergency Position } \\
\text { Indicating Radio Beacons } \\
\text { (EPIRB), Amateur radio }\end{array}$ \\
\hline $174-216$ & TV Channels 7 to 13 \\
\hline $216-400$ & $\begin{array}{c}\text { U.S. Military. Maritime Telcom, } \\
\text { Space Surveillance, ILS } \\
\text { Glideslope, Amateur }\end{array}$ \\
\hline $400-470$ & $\begin{array}{c}\text { Meteorological, Space, Missile } \\
\text { Defense, FRS, GMRS, Amateur, } \\
\text { Aero. Telephone }\end{array}$ \\
\hline $470-824$ & $\begin{array}{c}\text { TV Chan. 14 to 67, Medical } \\
\text { Telemetry, wireless mics, Pub/Priv } \\
\text { Mobile svcs, Radars }\end{array}$ \\
\hline $824-901$ & $\begin{array}{c}\text { Cellular Handsets \& Base Stations, } \\
\text { GTE AirFone, Private Land } \\
\text { Mobile }\end{array}$ \\
\hline $901-1000$ & $\begin{array}{c}\text { Cordless Phones, ISM, LMS, ITS, } \\
\text { Pub/Priv Mobile svcs, Fixed, U.S. } \\
\text { Govt., Aero. }\end{array}$ \\
\hline & \\
\hline & \\
\hline &
\end{tabular}

It was helpful to separate Fig. 5 into ten band-segments, and expand each one to reveal more detail in each RF frequency band. Data from two of these band-segments are shown in Figs. 6 and 7 where a data resolution of $500 \mathrm{kHz}$ and 2 seconds is utilized. [1] includes data from the other eight bands.

\section{A. $\quad 88 \mathrm{MHz}$ to $108 \mathrm{MHz}: \mathrm{FM}$ Broadcast Band}

The $88 \mathrm{MHz}$ to $108 \mathrm{MHz} \mathrm{RF}$ band is used exclusively for commercial FM radio broadcast. As illustrated by Fig. 6 this RF band is fully utilized. Another feature is significant reduction in received signal levels at ground level (after 500 seconds). Periodic signal level changes, particularly as seen in the $96 \mathrm{MHz}$ received signal data may be due to pattern shading and ground reflections. The aircraft antenna used for this ARMS flight is not expected to be very directional in this RF band. It is speculated that antenna pattern nulls may be due to line-of-sight shading by the airplane wings and fuselage. This shading is seen as periodic fading in the signal data.

\section{B. $108 \mathrm{MHz}$ to $138 \mathrm{MHz}$ : Aeronautical Band}

The $108 \mathrm{MHz}$ to $138 \mathrm{MHz}$ RF band shown in Fig. 7 is used exclusively for FAA licensed aeronautical radio. This RF band is critically important to aviation safety, and is expected to be free of interfering signals. Table 2 provides a summary of frequency allocations in the 108 to $138 \mathrm{MHz}$ band. Two distinctly different types of signals are used in this band: assigned communication channels that are used briefly and occasionally, and navigation beacons that are transmitting continuously. Table 3 contains a list of frequencies acquired during field evaluation.

The ILS localizer frequency (109.9 MHz) increases while approaching the runway, and then decreases upon passing the ground transmitter during landing. For navigation signals transmitted from other locations (i.e., 112.0, 116.9) Fig. 7 shows a continuous reduction in received signal levels as the altitude decreases. The very high (dark red) signal bursts are from the ARMS aircraft's own VHF radio transmitter. Similar, but lower-level VHF radio communications can be seen at other times and at other frequencies.

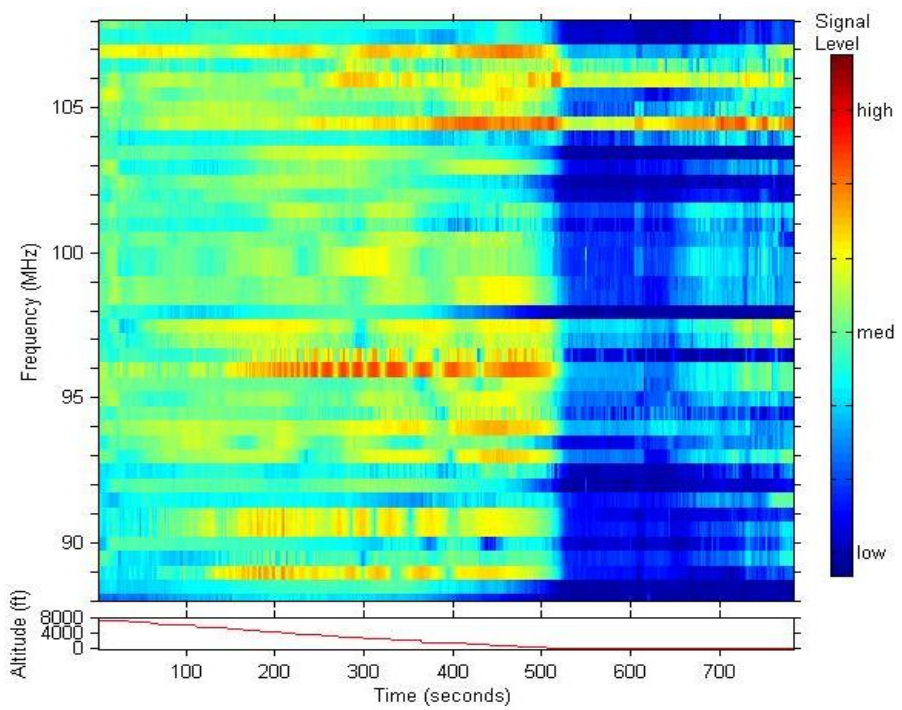

Figure 6: In-Flight Spectrum Environment for 88 to 108 $\mathrm{MHz}$.

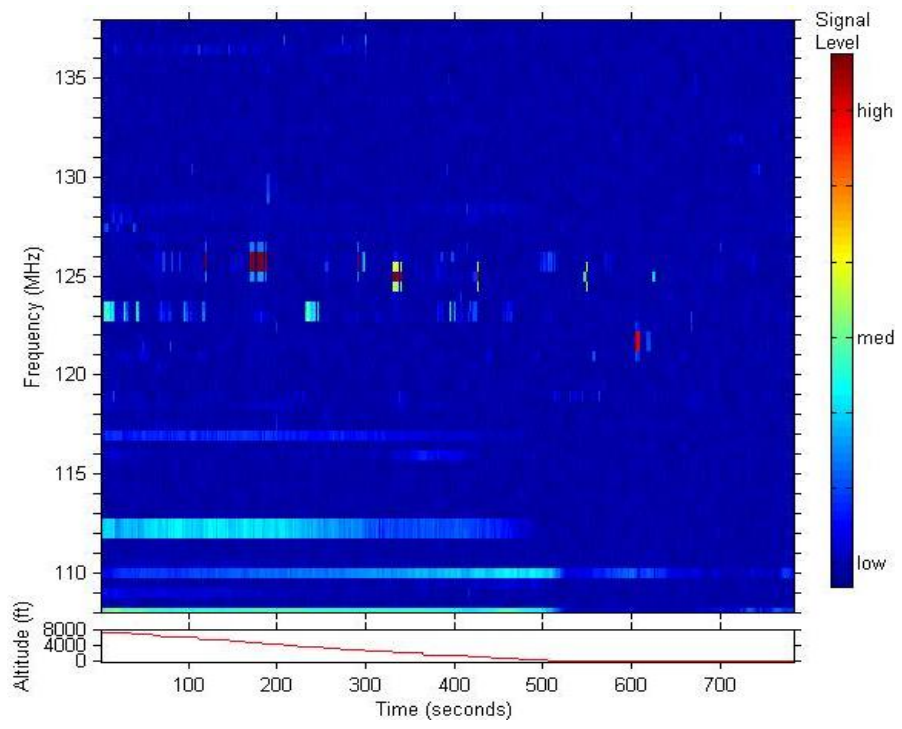

Figure 7: In-Flight Spectrum Environment for 108 to $138 \mathrm{MHz}$ 
Table 2: Frequency Allocation Summary for 108 to 138 $\mathrm{MHz}$

\begin{tabular}{|c|c|}
\hline Frequency (MHz) & Use \\
\hline $108-117.975$ & $\begin{array}{c}\text { Aeronautical radio Navigation } \\
(112-118 \text { MHz: VOR, ILS) }\end{array}$ \\
\hline $118-121.9375$ & $\begin{array}{c}\text { Aeronautical Mobile. Air Traffic } \\
\text { Controllers }\end{array}$ \\
\hline $\begin{array}{c}121.9375- \\
123.0875\end{array}$ & $\begin{array}{c}\text { Mobile units at airports. Unicom } \\
\text { weather data, flight service } \\
\text { communication }\end{array}$ \\
\hline $\begin{array}{c}123.5875- \\
138.8125\end{array}$ & VHF Air Traffic Control \\
\hline
\end{tabular}

Table 3: Local Aeronautical Frequency Listings (108 to $138 \mathrm{MHz})$

\begin{tabular}{|c|c|c|}
\hline $\begin{array}{c}\text { Frequency } \\
\text { (MHz) }\end{array}$ & $\begin{array}{c}\text { Modulation } \\
\text { Setting }\end{array}$ & $\begin{array}{c}\text { Description of Audible } \\
\text { Signal }\end{array}$ \\
\hline 108.8 & AM & VOR \\
\hline 109.1 & AM & ILS signal (nearby airfield) \\
\hline 109.9 & AM & Local Airfield ILS signal \\
\hline 110.1 & AM & Local Airfield ILS signal \\
\hline 112.0 & AM & VOR \\
\hline 112.2 & AM & VOR \\
\hline 116.9 & AM & VOR \\
\hline 118.7 & AM & $\begin{array}{c}\text { VHF COM Tower (nearby } \\
\text { airfield) }\end{array}$ \\
\hline 121.7 & AM & $\begin{array}{c}\text { VHF COM Ground } \\
\text { Operations }\end{array}$ \\
\hline 121.9 & AM & $\begin{array}{c}\text { VHF COM Ground } \\
\text { Operations }\end{array}$ \\
\hline 123.375 & AM & VHF COM NASA Operations \\
\hline 125.0 & AM & VHF COM Tower \\
\hline 125.7 & AM & Approach \\
\hline
\end{tabular}

VI. DATA CALIBRATION

The spectrum environment data graphs (figs. 5, 6 and 7) show un-calibrated RF survey data. This section explores how calibrations may be applied. Electric field intensities and/or available power levels in the surveyed airspace are dependent upon the type of aircraft antenna used, its orientation relative to each environmental transmitter, separation distance between each environmental transmitter and the ARMS antenna, the power output of each environmental transmitter, and the environmental transmitter antenna gain in the direction of the ARMS airplane. To determine the power measured at the ARMS spectrum analyzer input connector, the general transmission equation in $\mathrm{dB}$ is:

$$
\mathrm{P}_{\mathrm{Rcv}}=\left[\mathrm{P}_{\text {Source }}+\mathrm{G}_{\text {Source }}\right]-\mathrm{L}_{\text {Prop }}+\left[\mathrm{G}_{\mathrm{AC} \_ \text {Ant }}{ }^{--} \mathrm{L}_{\mathrm{Cb}}\right] \text {. }
$$

Where: $P_{\mathrm{Rcv}}\left(\mathrm{t}, \mathrm{f}, \mathrm{lat}_{\mathrm{rcv}}, \operatorname{lon}_{\mathrm{rcv}}, \mathrm{alt}_{\mathrm{rcv}}\right)=$ Power received at the aircraft radio connector for each frequency (f) and aircraft position (lat, lon, alt), at a given time (t); $\mathrm{P}_{\text {Source }}(\mathrm{t}, \mathrm{f}, \mathrm{n}$ lat $_{\text {source }}, \operatorname{lon}_{\text {source }}$, alt $\left._{\text {source }}\right)=$ Power transmitted from each environmental transmitter ( $n$ ) for each frequency (f) and source location (lat,lon,alt), at a given time (t).; $\mathrm{G}_{\text {Source }}(\mathrm{f}, \mathrm{n}, \theta$, $\varphi)=$ Environmental Source Antenna Gain, for each environmental transmitter (n), relative to isotropic, in direction of ARMS airplane; $\mathrm{L}_{\text {Prop }}\left(\mathrm{f}, \mathrm{n}, \mathrm{lat}_{\mathrm{rcv}}, \mathrm{lon}_{\mathrm{rcv}}\right.$, alt $\mathrm{rcv}_{\mathrm{rc}}$, lat $t_{\text {source }}, \operatorname{lon}_{\text {source }}$, alt $\left._{\text {source }}\right)=\mid$ Propagation loss $\mid$ between each signal source (n) and aircraft antenna, for each frequency (f); $\mathrm{G}_{\mathrm{AC} \_ \text {Ant }}(\mathrm{f}, \mathrm{n}, \theta, \varphi)=$ Aircraft Antenna Gain, relative to isotropic, in direction of signal source; and $\mathrm{L}_{\mathrm{Cbl}}(\mathrm{f})=$ |Onboard Cable loss|. All variables are in dB units.

Note that $\mathrm{P}_{\mathrm{Rcv}}, \mathrm{P}_{\text {Source }}$ and $\mathrm{L}_{\text {Prop }}$ are also functions of position (latitude, longitude and altitude) of the ARMS aircraft when the measurement occurred. The ARMS data files correlate timestamp information with latitude and longitude for each $\mathrm{P}_{\mathrm{Rcv}}$ data point.

Propagation loss is a standard quantity and is given in $\mathrm{dB}$ as:

$\mathrm{L}_{\text {Prop }}=20 \log [4 \pi \cdot$ Distance $\cdot \mathrm{f} / \mathrm{c}]$.

Where: $c=$ Velocity of signal propagation which is usually assumed equal to light in free space, $c=3 \times 10^{8}$ meters/sec; $\mathrm{f}=$ Radio frequency of operation in $\mathrm{Hz}$; Distance $\left(\mathrm{n}, \mathrm{lat}_{\mathrm{rcv}}, \operatorname{lon}_{\mathrm{rcv}}, \mathrm{alt}_{\mathrm{rcv}}\right.$, lat $_{\text {source }}, \operatorname{lon}_{\text {source }}$, alt $\left._{\text {source }}\right)=$ Separation distance between transmitter (n) antenna and ARMS aircraft antenna in meters; Distance is automatically calculated from the ARMS aircraft latitude, longitude and altitude (and time), and recorded for each measurement, when the transmitter location is known.

It is important to address efficiency (reflection and resistive loss) as part of $\mathrm{G}_{\mathrm{AC} \_ \text {Ant }}$, if measuring outside its design frequency band. $\mathrm{G}_{\mathrm{AC} \_ \text {Ant }}$ consists of three components $(\mathrm{dB})$ :

$$
\mathrm{G}_{\mathrm{AC} \_ \text {Ant }}=\mathrm{D}_{\mathrm{AC} \_ \text {Ant }}-\mathrm{L}_{\mathrm{Refl}}-\mathrm{L}_{\mathrm{Res}} \text {. }
$$

Where: $D_{A C}$ Ant $(f)=$ Directivity of the Aircraft Antenna; $\mathrm{L}_{\text {Refl }}(\mathrm{f})=$ Reflection Loss of the Aircraft Antenna; and $\mathrm{L}_{\text {Res }}(\mathrm{f})=$ Resistive Loss of the Aircraft Antenna.

Reflection loss $\mathrm{L}_{\text {Refl }}(\mathrm{f})$ and resistive loss $\mathrm{L}_{\text {Res }}(\mathrm{f})$ may be significant for an antenna operating outside its design frequency band. Also, when an antenna is used at higherthan-intended frequencies, nulls occur in the directivity pattern. It is therefore useful to address aircraft antenna "inband" differently from aircraft antenna "out-of-band" ARMS measurements.

The primary purpose of the ARMS was to directly measure ILS signal coverage around airports (i.e. $\mathrm{P}_{\mathrm{Rcv}}$, with some prior knowledge of $\mathrm{P}_{\text {Source }}$ and $\left.\mathrm{G}_{\text {Source }}\right)$. Other applications may include detecting and characterizing power output, antenna patterns, locations and operating frequencies of ground sources. The next section describes the aircraft antenna in-band calibration scenario for an ILS IAP. Aircraft antenna out-of-band calibration was not required for the experiment data shown in this report, however some general guidelines for such a calibration are provided in [1].

\section{ILS LOCALIZER AND GLIDESLOPE MEASUREMENT RESULTS}

The ARMS measured the LOC and GS RF signal levels in an ILS approach path. During the airport RF measurement survey, the ARMS included a Comant CI 159C 
dual-band V-Dipole antenna. This particular antenna is specifically designed for LOC and GS, and has a VSWR of 3:1 or less in both RF bands. This is the simplest calibration scenario because the aircraft antenna design and installation are optimized to minimize reflection and resistive loss for the frequencies-of-interest, and to provide a known directivity toward the intended transmitter during an ILS approach.

For the ARMS installation, a spectrum analyzer used the navigation input for the \#2 Apollo SL-30 navigation and communication radio. The cable loss difference between the spectrum analyzer cable and the SL-30 \#2 cable is negligible (less than $1 \mathrm{~dB}$ ) in the ILS RF bands. So, for the purpose of comparing available ILS signal levels at the spectrum analyzer versus the aircraft radio receiver, no calibration factors are required.

To evaluate the signal coverage volume of the airport ILS services $\left[\mathrm{P}_{\text {Source }}+\mathrm{G}_{\text {Source }}-\mathrm{L}_{\text {Prop }}\right]$, it is necessary to consider the Mini-Circuits zfsc-2-1b RF power divider loss (about $3 \mathrm{~dB}$ ), the aircraft antenna cables (about $3 \mathrm{~dB}$ ) and the Comant CI $159 \mathrm{C}$ antenna gain $\left(\mathrm{G}_{\mathrm{AC} \_ \text {Ant }}=\sim 0 \mathrm{dBi}\right)$. Using (1), we can obtain the ILS signal power available at a particular aircraft location. The ARMS can be connected to any other aircraftmounted antenna.

Using an approach and landing data sample, the specific frequencies for ILS localizer and ILS glideslope are plotted in Fig. 8. The signal levels are shown to gradually increase while approaching the runway. As the aircraft passed the localizer and glideslope antenna arrays during final descent, the signal levels fall dramatically. Once on the ground, data continued to be collected for about 250 seconds as the aircraft taxied down the runway, exited the runway, and proceeded to a nearby hangar. The Distance-to-Runway is calculated and defined as the distance measured between the runway reference coordinates (end point) and the aircraft's location. In Fig. 8 the Distance-to-Runway (plotted in blue) is overlaid by the Altitude (plotted in green) before the runway reference point and cannot be seen in the graph. The two are closely correlated due to the constant glideslope. The "jumps" in Distance-to-Runway and Altitude are caused by periodic updates in the GPS position.

$\mathrm{L}_{\text {Prop }}$ can be calculated using (2), which uses Distance as recorded in the data files. The ILS ground beacon EIRP $\left[\mathrm{P}_{\text {Source }}+\mathrm{G}_{\text {Source }}\right]$ can then be determined from data shown in Fig. 8. (It is important to note that $\mathrm{G}_{\text {Source }}$ is no longer constant after the airplane passes the ILS LOC and GS antennas and taxis away from the runway.)

\section{OBSERVATIONS AND RECOMMENDATIONS}

The purpose of the ARMS is to provide a resource for environmental electromagnetic hazards research under the Integrated Vehicle Health Management (IVHM) element of NASA's Aviation Safety Program, and to be used to evaluate high-intensity radiated fields (HIRF) threats and aeronautical RF spectrum encroachment in the NAS. The ARMS can be used to identify signals and signal strengths in specified locations and to explore suspected interference situations.

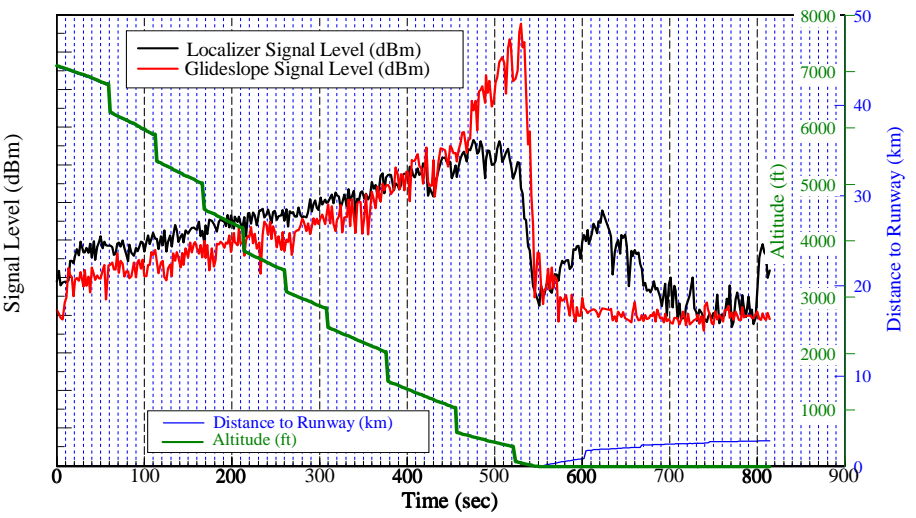

Figure 8: In-Flight localizer and glideslope levels on ILS approach.

The ARMS provides an automated data acquisition capability to capture and record maximum signal levels, as well as an entire SA measurement trace of 401 to 8,192 data points. All signal levels measured are coordinated with GPS coordinates and time stamped at the moment of acquisition. As a result, a comprehensive study can be made of the environment surveyed using full trace data correlated with location.

The LaRC Lancair aircraft was well suited for development of the ARMS because it contained ILS and VOR approach instrumentation and a GPS antenna and receiver. ARMS can be adapted to other similar aircraft.

\section{REFERENCES}

[1] S. V. Koppen, J. J. Ely, L. J. Smith, R. A. Jones, V. J. Fleck, M. T. Salud, J. Mielnik, "Airborne RF Measurement System (ARMS) and Analysis of Representative Flight RF Environment", NASA TP Xxxxx, to be published January 2007.

[2] Howell, C.T., III; Shelton, K.J.; Fisher, B.D.; Gallaher, D.A.; Johnston, S.L.; Rush, H.F., Jr.; Smith, C.D.; Trombetta, "The NASA Langley Research Center's General Aviation Baseline Research System", Proceeding of $22^{\text {nd }}$ Digital Avionics Systems Conference 2003, Volume 2, October 12 - 16, 2003.

[3] FAA CFR Title 14: Aeronautics and Space, Part 23 "Airworthiness Standards: Normal, Utility, Acrobatic, and Commuter Category Airplanes", FAR 23.561 General, October 2006.

[4] FAA Advisory Circular AC43.13-2A: "Acceptable Methods, Techniques, and Practices - Aircraft Alterations": Chapter 1"Structural Data", Revision 1977.

[5] FAA CFR Title 14: Aeronautics and Space, Part 23 "Airworthiness Standards: Normal, Utility, Acrobatic, And Commuter Category Airplanes", FAR 23.785: Personnel and Cargo Accommodations, Seats, berths, litters, safety belts, and shoulder harnesses", October 2006.

[6] Bennett Z. Kobb, Wireless Spectrum Finder, McGraw-Hill, 2001, ISB 0-07-137506-6. 